\title{
Neonatal bullous mastocytosis
}

\section{Naik Piyu Parth}

\author{
Department of Dermatology, Saudi German Hospital and Clinics, Opposite of Burj Al Arab, Dubai, United Arab Emirates.
}

Corresponding author: Naik Piyu Parth, MD, E-mail: drpiyu85@gmail.com

\begin{abstract}
I am reporting a 17-day old female neonate attended in an emergency with a history of generalized multiple bullous lesions all over the body with spontaneous ruptures of these bullous lesions resulting in erosions and healing with dark pigmentations. Provisional clinical diagnoses were bullous mastocytosis or congenital syphilis. Hematological investigations were against the diagnosis of congenital syphilis. The skin lesion's biopsy with an array of histopathological staining and immunohistochemical typing confirmed the diagnosis of diffuse cutaneous erythrodermic mastocytosis. The attending clinician should know the process of evoking bullous mastocytosis in front of pruritic blisters associated with dermographism. Enlarged bullous form of the disease should be considered an emergency and dealt with urgency.
\end{abstract}

Key words: Bullous mastocytosis; Bullous dermatoses; Neonatal skin bullae; Pediatric dermatoses, Neonatal dermatoses

\section{INTRODUCTION}

Mastocytosis is characterized by abnormal mast cell proliferation and accumulation within various organs, most commonly the skin [1]. Though mastocytosis is a rare entity, the majority of cases are in the pediatric age group. Children account for two-thirds of the caseload world-wide-dermatological manifestations, either in pigmentary urticaria or mastocytoma form, present in 90 $\%$ of cases. Diffuse mastocytosis has an incidence of just less than $10 \%$ among pediatric cases, with the highest frequency of bullous form in the majority of cases [2].

\section{CASE REPORT}

A 17 days old Asian female neonate was referred to the emergency department for a history of multiple fluid-filled lesions all over the body since birth with spontaneous rupture of these lesions over the next few days resulting in erosions and healing with dark pigmentations.

Neonate was born by full-term vaginal delivery, and parents were in a non-consanguineous marriage. The mother also gave a jaundice history from the $3^{\text {rd }}$ day of her life and denied any genital lesions or rash in herself.
The neonate was quite irritable on general examination, and icterus was identified in the sclera, while no lymphadenopathy or hepatosplenomegaly was seen. Dermatological examination showed generalized bilateral asymmetrical, polymorphic erosions along with erythematous plaques and hyperpigmentation patches in varying stages. Darier's sign and Nikolskys signs were negative (Figs. la - lc).

Mucous membranes, palmar regions and planter regions were free of disease. Differentials for provisional diagnosis were bullous mastocytosis and congenital syphilis. Hematological investigations were advised, which showed complete blood count in a normal range and negative serum VDRL for mother and neonate. Precautionary Ultrasonography of the abdomen of the neonate was also normal. Though hematological investigations were against the diagnosis of congenital syphilis and bullous mastocytosis was the most likely diagnosis, a cutaneous biopsy from a few of these skin lesions was done.

After Hematoxylin, Giemsa and Toluidine blue staining, histopathological findings showed epidermolysis with perivascular mononuclear infiltrates with multiple areas of mast cells in the superficial dermis (Figs. 2a-2d).

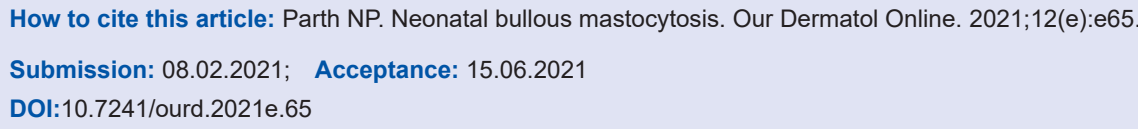




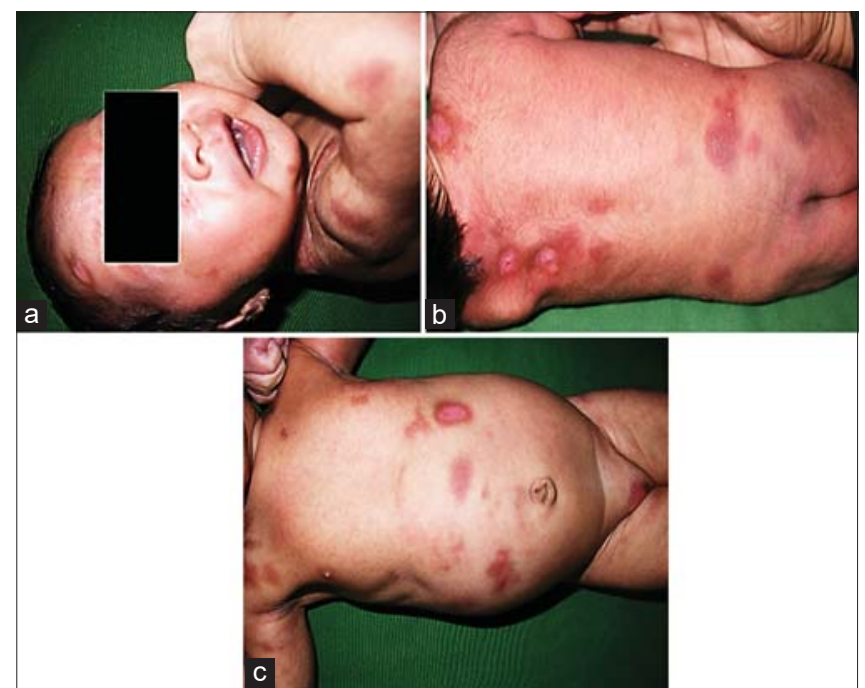

Figure 1: (a) Erythematous plaques with hyperpigmentation seen over face and right upper limb (b) Erythematous plaques with hyperpigmentation seen over the entire back, (c) Erythematous plaques with hyperpigmentation seen over chest, abdomen, genital region and thighs.

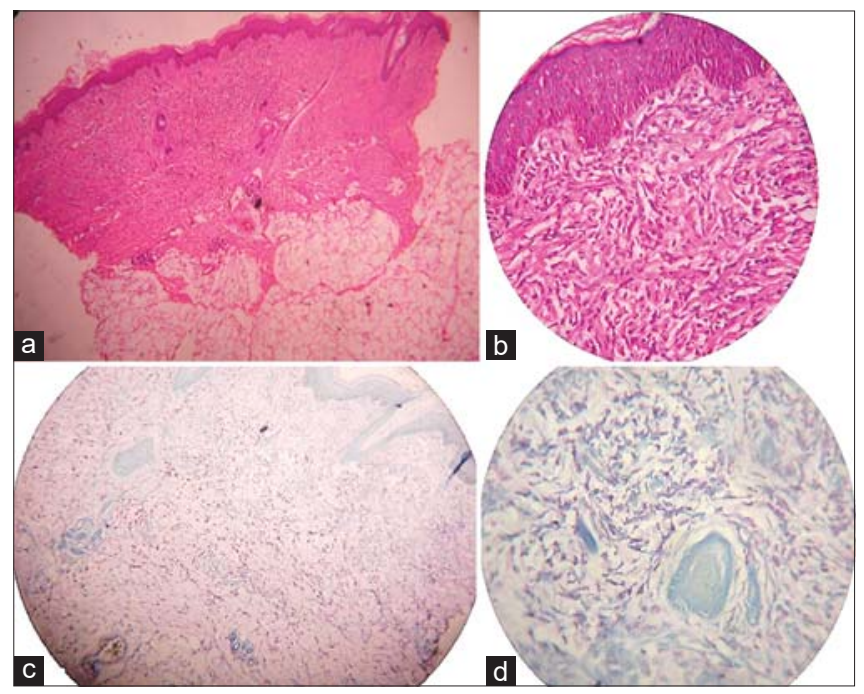

Figure 2: (a) Histopathological findings of cutaneous biopsy after hematoxylin staining showed epidermolysis with perivascular cell infiltrates (magnification 100X). (b) Histopathological findings of cutaneous biopsy after hematoxylin staining showed epidermolysis with perivascular cell infiltrates (magnification 200X). (cd) Histopathological findings of cutaneous biopsy after Giemsa and Toluidine blue staining showed granules in the cytoplasm of mast cells (magnification 100X for left and $300 \mathrm{X}$ for right image).

The consulting pathologist advised immunohistochemical typing (IHC) to reach for the histopathological diagnosis, which ultimately was positive for CDl17 marker (Fig. 3).

The pathologist stated mastocytosis as a diagnosis; hence the final diagnosis of diffuse cutaneous erythrodermic mastocytosis was made. C-kit receptor mutation was positive on further evaluation and was

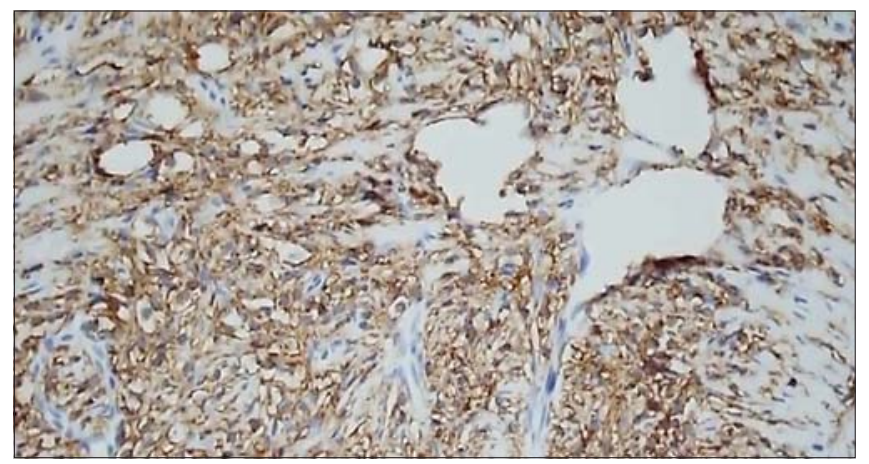

Figure 3: Immunohistochemical typing mast cells were positive for CD117: mastocytosis.

identified as a primary culprit for pathogenesis. No systemic sign was seen, which ruled out the systemic involvement in this case. Serum tryptase value was elevated $25 \mathrm{ng} / \mathrm{mL}$.

The patient was put on systemic Betamethasone therapy with a daily dose of $1 \mathrm{mg} / \mathrm{kg} /$ day. Ketotifen $0.06 \mathrm{mg} / \mathrm{kg}$ was also given for one week as a mast cell stabilizer and antihistaminic properties. Taping of steroid was performed over four weeks without any observed side-effect. Reduction in erythematous areas and hyperpigmentation was observed in a follow-up visit after two weeks. Parents also stated a significant reduction in irritability during a follow-up consultation. Parents were educated on avoiding any allergic stimuli in the future and using betamethasone syrup, epinephrine autoinjector if any emergency related to the same diagnosis arises subsequently. Informed parents' consent was taken for the case report in the follow-up visit.

\section{DISCUSSION}

Mast cells emerge from the bone marrow and possess several mediators having many repercussions in many body organs [3]. Generally, mastocytosis presents before the age of 2 years, but neonatal cases are exceedingly rare [4]. Rarity in neonates makes this case presentable as dermatologists and pediatricians do not think as a differential in the initial days of life. Mutation in the c-Kit receptor is the etiology behind the disease present in most children. (Fig. 4) Autosomal dominant transmission with variable penetrance has been observed rarely [5].

Skin manifestations are most common $(90 \%)$ and can be in the clinical form of pigmented urticaria (PU), mastocytoma, eruptive telangiectasia, macularis perstans and diffuse cutaneous mastocytosis [6].All these variants 


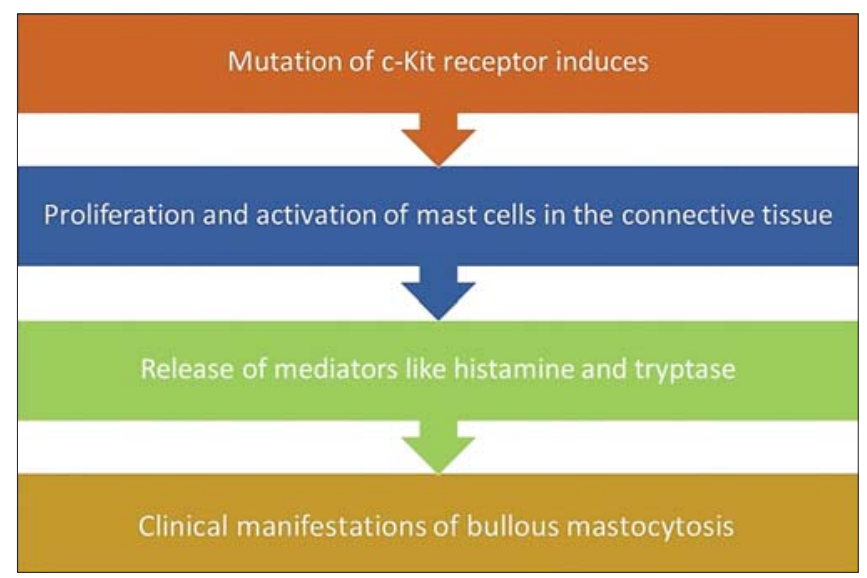

Figure 4: Etiopathogenesis of bullous mastocytosis.

of mastocytosis can manifest as bullous skin lesions. However, when the bullous form is predominant, it is referred to as bullous mastocytosis (BM). A massive release of chymase and cathepsin $\mathrm{G}$, which is followed by secretion of heparin by mast cells due to mast cell granulation, leads to breakage of the dermal-epidermal junction skin and instigates bullous detachment [2]. This phenomenon is also associated with a high risk of mortality [2,5]. BM presents with frequent systemic involvement [7]. Bones, spleen, liver and gastrointestinal tract are affected in systemic involvement [6].

Cardiovascular manifestations like flushing, hypotension, tachycardia and shock are also not uncommon in systemic involvement cases. These manifestations result from mediators secreted by mast cells, which are abnormally proliferated and activated in mastocytosis. Many agents, which stimulate these abnormal mast cells, including non-steroidal anti-inflammatory medicines, histamine rich foods like crustaceans, peas and histamine liberator foods such as citrus foods, can also lower the threshold for manifestations. Surgical intervention, stress, insect bite and infections are also considered trigger points. Hence, avoidance or treatment of stimuli is one of the management strategies for bullous mastocytosis $[5,8]$.

Initial manifestations of general, cutaneous involvement emerge as the skin's infiltrated area with a paste-like consistency. Early lesions can be nodular or urticarial papules too. Pruritus is markedly severe and found in almost two-thirds of cases in children [9].

Serum tryptase value greater than $20 \mathrm{ng} / \mathrm{mL}$ is an excellent tool to assess mast cell proliferation and bone marrow infiltration, but tryptase values are also elevated in myeloid hemopathies, urticaria and anaphylactic shock, which makes serum tryptase test less sensitive $[10,11]$. This case also showed a border-line value of serum tryptase in the gray-zone. Hence, histopathology is the gold standard for diagnosis along with clinical findings $[8,12]$. Hematological abnormalities, shock, multi-organ failure or diffuse cutaneous mastocytosis with hepatosplenomegaly, lymphadenopathy warrant further evaluation in children $[1,10]$.

Though the prognosis of the neonatal form is restrained, this neonate fared quite well and recovered. Cutaneous findings in children generally resolve spontaneously without any scar. However, many show the persistence of residual skin lesions with dermographism and postinflammatory pigmentation $[11,14]$.

Management of bullous mastocytosis is multi-factorial. While avoidance of triggering factors, which evoke the mast cell degranulation, forms the first line of management. Systemic antihistamines and topical corticosteroids, along with mast cell stabilizers like Ketotifen, forms a formidable force. Severe cases require systemic corticosteroids. Tyrosine kinase inhibitor - Imatinib mesylate has shown benefit in a few cases. Secondary infection should be treated with antiseptics. Known cases of previous primarily bullous mastocytosis with shock or profound hypotension require prompt administration of adrenaline injection in the strength of 1:1000. Adrenaline autoinjectors are also a good option for parents $[2,5,10,13,14]$.

\section{CONCLUSION}

In culmination, diffuse cutaneous erythrodermic mastocytosis is an acute and severe form of cutaneous mastocytosis commonly seen in children - this clinical case presented in the neonatal period with high morbidity. Though bullous mastocytosis is not commonly seen in neonates, it is prudent to keep that in the differential diagnosis. Clinicians should be aware of the process of eliciting bullous mastocytosis in front of pruritic blisters linked with dermographism. The clinician should know that systemic features need further evaluation and associated anaphylaxis is an acute emergency. Parents should be educated at every step of management and made aware of warning signs and adrenaline administration at a critical time.

\section{Consent}

The examination of the patient was conducted according to the principles of the Declaration of Helsinki. 
The authors certify that they have obtained all appropriate patient consent forms, in which the patients gave their consent for images and other clinical information to be included in the journal. The patients understand that their names and initials will not be published and due effort will be made to conceal their identity, but that anonymity cannot be guaranteed.

\section{REFERENCES}

1. Torrelo A, Alvarez-Twose I, Escribano L. Childhood mastocytosis. Curr Opin in Pedia. 2012;24:480-6.

2. Bankova LG, Walter JE, Iyengar SR, Lorenzo ME, Hornick JL, Castells MC. Generalized bullous eruption after routine vaccination in a child with diffuse cutaneous mastocytosis. J Alle Cli Immuno: In Practice. 2013;1:94-6.

3. Metcalfe DD. Mastocitose. In: Goldman L, Benett JC. Tratado de Medicina Interna. 21a ed. Rio de Janeiro: Guanabara Koogan; 2001;1634-6.

4. Das D, Sardar ADS. Childhood bullous mastocytosis. Indian Ped. 2013;50:1073-4.

5. Lucky AW, Prendiville JS, Tay YK, Kwok YK, Lee YS. Generalized Bullous Eruption in an Infant. Pedia Dermatol. 2005;22:79-81.

6. Kaatz M, Barta U, Wollina U. Mastocitose cutánea difusana infancia: tratamento bem sucedido com PUVA. An Bras Dermatol. 2000;75:737-43.

7. Hartmann K, Metcalfe DD. Pediatric mastocytosis. Hematol Oncol Clin North Am. 2000;14:625-40.
8. Kiszewski AE, Durán-Mckinster C, Orozco-Covarrubias L, Gutiérrez-Castrellón P, Ruiz-Maldonado R. Cutaneous mastocytosis in children: a clinical analysis of 71 cases. J Eur Acad Dermatol Venereol. 2004;18:285-90.

9. Bérénice D, Christiane K, Alida K, Nadège A, Alain G, Fabrice A, et al. A diffuse bullous cutaneous mastocytosis mimicking a bullous toxidermia in a black child. J Cli Exp Dermatol Res. 2019;10:1000486.

10. Kleewein K, Lang R, Diem A, Vogel T, Pohla-Gubo G, et al. Diffuse cutaneous mastocytosis masquerading as epidermolysis bullosa. Pediatr Dermatol. 2011;28:720-5.

11. Leblanc L, de Monléon JV, Faber V, Beer F, Dalac S, E Justrabo, D Lambert, F Huet. Mastocytose cutanée bulleuse révélée par un malaise grave secondaire à la prise de morphinique. Arch Pédiatr. 2001;8:512-5.

12. Fraitag-Spinner S. Mastocytoses cutanées. Ann de Dermatol Venereol. 2007;134:589-92.

13. Deverrière G, Carré D, Nae I, Cailliez D, Boulloche J. Mastocytose bulleuse diffuse du nourrisson: une forme clinique rare. Arch Pédiatr. 2012;19:722-5.

14. Avshalumov K, Pichardo R, Jorizzo JL, Sangueza OP, Goldenberg G. Bullous mastocytosis: Report of a patient and a brief review of the literature. Am J Dermatopathol. 2008;30:455-7.

Copyright by Naik Piyu Parth. This is an open access article distributed under the terms of the Creative Commons Attribution License, which permits unrestricted use, distribution, and reproduction in any medium, provided the original author and source are credited.

Source of Support: Nil, Conflict of Interest: None declared. 